\title{
O CUIDADO DE SI E DIFERENÇAS NA EDUCAÇÃO INFANTIL
}

\author{
Gabriela Tebet ${ }^{1}$
}

\section{Introdução}

Nesta seção do dossiê reunimos textos que abordam a educação infantil, os estudos de bebês e as artes, a partir do diálogo com as ideias de Foucault presentes no livro A hermenêutica do sujeito. Nesse sentido, diferentes linhas de reflexões são traçadas. Loani Buzo nos oferece algumas reflexões sobre o cuidado como ética e o papel dos educadores em contexto de educação infantil; Natália Santos parte da narrativa de Foucault em torno de Alcebíades traça linhas paralelas relativas às práticas educativas da Educação Infantil, tendo como foco a experiência de ser um bebê ou uma criança negra na creche; e, por fim, ainda nessa seção. Estes textos nos instigam a pensar em diferentes aspectos da educação de crianças que podem ser pensados a partir da noção cuidado de si.

Antes delas, algumas outras pesquisas já se debruçaram sobre o tema do cuidado de si articulando-o com questões relativas à infância. Dentre elas, destacamos o trabalho de Nakano e Mamede (1999), Freitas (2010), Pagni (2010) e Guimarães (2011). Outras pesquisas, como as desenvolvidas por Gottlieb e colaboradoras, apesar de não mobilizarem o pensamento de Foucault, nos oferecem dados bastante ricos para pensarmos o cuidado de si na educação de povos em distintas sociedades. Esperamos, assim, com os textos que compõem essa sessão do dossiê, contribuir para a construção de pensamentos sobre cuidado de si, bebês, infância e educação.

\section{Diálogos com Foucault para discutir o cuidado de si e a questão da diferença}

De modo geral, o curso de Foucault intitulado A hermenêutica do sujeito, nos apresenta um conjunto de formas como a questão do cuidado de si foi percebida em diferentes contextos e momentos históricos.

As passagens da obra de Foucault que fazem menção ao texto platônico intitulado Alcibíades evidenciam uma concepção de que cuidar de si é cuidar da alma e do elemento divino que ela carrega e que permite acessar a verdade divina. Também destacam que Alcibíades possuía "privilégios ancestrais" e que desejava "transformar seu status privilegiado, sua primazia estatutária, em ação política, em governo efetivo dele próprio sobre os outros" (FOUCAULT, 2011, p. 32). De acordo com Foucault,

Primeiramente, como vemos, a necessidade de cuidar de si está vinculada ao exercício do poder (...) a questão do cuidado de si não aparece como um dos aspectos de um privilégio estatutário. Aparece, ao contrário, como uma condição, condição para passar do privilégio estatutário que era o de Alcibíades (grande família rica, tradicional, etc.) a uma ação política definida, ao governo efetivo da cidade. Como vemos, 'ocupar-se consigo' está, porém, implicado na vontade do indivíduo exercer o poder político sobre os outros, e dela decorre. Em segundo lugar, (..) está vinculada à insuficiência de educação de Alcibíades (...) Em terceiro lugar, (...) é preciso aprender a ocupar-se consigo quando se está naquela idade crítica, quando se sai das mãos dos

\footnotetext{
${ }^{1}$ Doutora em Educação (UFSCar, 2013). Professora do DECISE-FE-Unicamp - Campinas-SP e integrante dos grupos de pesquisa GPPES e DiS. Coordenadora do grupo de estudos BebÊEEducação. E-mail: gabigt@unicamp.br.
} 
pedagogos e se está para entrar no período da atividade política. [mas] Até certo ponto, este texto está em contradição, ou afinal coloca um problema (...) relativamente a outro (...) da Apologia de Sócrates, quando Sócrates diz, ao defender-se diante de seus juízes: mas meu ofício em Atenas (...) consistia em postar-me lá, na rua, e interpelar todo mundo, jovens e velhos, cidadãos ou não cidadãos, para dizer-lhes que se ocupassem consigo mesmos. Ali a hepiméleia heautô̂ aparece como uma função geral de toda a existência, ao passo que no Alcibíades aparece como um momento necessário na formação do jovem (p. 34-36).

Pois bem: algumas questões são importantes de serem suscitadas a quem nos lê e deseja pensar o cuidado de si no campo dos estudos da infância, da educação infantil, ou dos bebês.

A primeira delas, diz respeito ao exercício do poder por diferentes grupos geracionais o que poderia ser pensado na sociedade, de modo geral ou em diversas sociedades, de modo concreto. Quando Foucault destaca na passagem anteriormente transcrita que ocupar-se consigo implica na "vontade do indivíduo exercer o poder político sobre os outros, e dela decorre", inicialmente poderíamos supor que, portanto, ocupar-se consigo é tarefa exclusiva dos adultos, uma vez que bebês e crianças não exercem poder político sobre os outros. Contudo, tal suposição poderia ser questionada em face à noção desenvolvida pelo próprio Foucault (1979) de que o poder não se restringe ao Estado e a seus governantes, e que existe uma microfísica do poder que se dilui por toda a sociedade. O poder, para Foucault, é uma prática social que está em toda parte, não se identificando com uma instituição ou pessoa. Os relatos de Gottlieb sobre os bebês Beng na Costa do Marfim são um bom exemplo de como as relações de poder não necessariamente possuem a mesma estrutura em todas as sociedades e de como os bebês podem ter um status bastante especial nas relações de poder.

A segunda, diz respeito à definição da idade a partir da qual se deve cuidar de si mesmo.

O excerto da discussão realizada por Foucault e transcrito anteriormente evidencia uma contradição entre a atividade de Sócrates como mestre do cuidado de si e que indica que o cuidado de si deve ser uma preocupação de todos, e a indicação no texto Alcibíades que indica que o cuidado deve acontecer apenas na juventude. Nem antes e nem depois. Destaca ainda que um texto epicurista, Carta a Menescau, inicia-se com a afirmação de que "Nunca é demasiado cedo nem demasiado tarde para ter cuidados com a alma" (2011, p. 444) e que segundo Galeno "é melhor ter, desde a mais tenra idade, velado pela própria alma" (2011, p. 445).

Faz-se pertinente atentarmos para o fato de que o modo como cada sociedade concebe o sujeito e sua relação com o mundo espiritual de algum modo, define quem são aqueles e aquelas aptos a cuidar de si mesmo e desempenhar um papel de maior poder na sociedade. E ainda, que o modo como o sujeito é compreendido em cada sociedade define o modo como os bebês e as crianças são compreendidos, bem como as práticas de cuidados a eles destinadas. Assim, as concepções que orientam os guias de cuidados infantil de sete distintas sociedades (DELOACHE; GOTTLIEB, 2000) são instigadoras e nos provocam um conjunto de reflexões sobre a pertinência ou não de falarmos sobre cuidado de si, quando nos referimos aos bebês, por exemplo.

Em terceiro lugar, destaco a importância de pensarmos sobre o papel da educação formal e de seus profissionais na educação do ser humano bem como de avaliarmos a existência de um déficit pedagógico na educação de bebês, crianças e jovens e ainda, de discutirmos o papel desempenhado pelas famílias em relação à educação e ao cuidado de si de todos os seus membros.

E por fim, questiono se seria possível estabelecermos alguma relação entre a ação de Sócrates ao se assumir como mestre do cuidado de si preocupado em interpelar a todos nas ruas, sem exceção, com as atuais discussões sobre a educação como um direito de todos e sua 
necessidade de aprender a receber e respeitar as diferenças. Textos recentes têm apontado para o fato de que políticas de promoção da diversidade não são efetivas para atender às diferenças.

Nesse sentido, Oliveira e Abramowicz (2013) apontam que o conceito de diversidade tem assumido nas políticas públicas para a educação, o papel de uma armadilha conceitual e uma estratégia política de esvaziamento e/ou apaziguamento das diferenças e das desigualdades. Do mesmo modo, Gallo (2017b, p. 1513) afirma, que "tomar a diversidade em lugar da diferença significa 'domar' a diferença, apaziguá-la, neutralizar os horrores que o efetivamente diferente poderia provocar.” Por fim, Abramowicz e Tebet (2017) ao discutir o lugar da diferença no currículo da educação infantil e a Base Nacional Comum Curricular, afirmam que "uma BNCC pretende expurgar a diferença. E por que a Educação Infantil necessita de uma base comum? A nosso ver, para que um tipo de infância se realize sobre todas as crianças, sem que elas mesmas possam se interrogar sobre ela" (p. 196). As autoras afirmam ainda que

Neste momento de retrocesso do Estado de direito e democrático em que vivemos
hoje, há um refluxo substantivo dessa pauta e da ascensão de todas as formas de
fascismos. Novamente se disputa a identidade nacional, de maneira a colocar a
diferença e/ou a diversidade como aberração e desvio e, se possível, aboli-las do
espaço público e educacional, como ocorreu, por exemplo, na interdição do
debate sobre as relações de gênero que tão contundentemente foi colocada no
processo de aprovação dos Planos Estaduais e Municipais de Educação
(ABRAMOWICZ e TEBET, 2017, p. 197).

A partir da perspectiva de provocar e instigar o cuidado de si por todos, tal como fazia Sócrates na rua, e frente às ideias sobre o lugar da diferença na educação, questionamos se seria a escola capaz de permitir e promover uma conduta ética que viabilizasse o cuidado de si fora das práticas de governamentalidade que visam tornar a todos um povo uniforme? Seria possível oferecermos a todos (bebês, crianças, mulheres, negros, gays, deficientes etc.), apoio e orientação para a realização de práticas de si capazes de fortalecer a constituição de subjetividades singulares? Seria possível pensarmos em práticas de si constituidoras de diferença?

Para nos oferecer algum ponto de partida a fim de incitar novas pesquisas que se debrucem sobre tais questões, aponta-se para o destaque feito por Foucault (2011) quando afirma que "devemos considerar que relações de poder/ governamentalidade/ governo de si e dos outros/ relação de si para consigo compõem uma cadeia, uma trama e que é em torno dessas noções que se pode, ao meu ver, articular a questão da política e a questão da ética" (p. 225).

\section{Cuidado de si, bebês, infância e Educação Infantil}

A articulação da noção cuidado de si para pensar temas relativos à infância e à educação vem sendo realizada por um conjunto de textos, como destacado anteriormente. Selecionamos alguns deles para traçar um panorama do que tem sido produzido sobre o assunto.

O texto mais antigo que localizamos e que faz essa articulação foi publicado por Nakano e Mamede (1999). As autoras discutem a prática do aleitamento materno em um grupo de mulheres brasileiras como movimento de acomodação e resistência. $\mathrm{O}$ estudo visou apreender os significados que as mulheres atribuem às vivências e demandas na prática do aleitamento materno e a discussão fundamenta-se na teoria feminista com importantes articulações com o pensamento Foucaultiano. O conceito "cuidado de si" é mobilizado para pensar a ação das mulheres em relação a si e ao seu corpo durante o período de aleitamento e o desmame frente às dificuldades vividas pelas mulheres durante o processo é interpretado como uma atitude de resistência em relação a um poder instituído. 
Guimarães (2011), por sua vez, mobiliza as relações entre sujeito e verdade que perpassam o debate sobre cuidado de si realizado por Foucault para pensar os bebês, a relação entre estes e os adultos e para problematizar o conceito de cuidado que circula nas creches. Nesta obra, a autora descreve "como a inscrição cultural acontece, produzindo subjetividade" e "como os bebês vão sendo conduzidos a ter uma experiência de si mesmos no contexto dos objetos, dispositivos, rotinas e práticas da creche", mas reconhece que "é um desafio buscar a experiência de si num momento em que o si mesmo está sendo construído na relação com o outro. É como se o bebê vivesse o espaço entre o mundo objetivamente percebido e o mundo subjetivo" (p. 24).

Em face a tal desafio, Guimarães nos instiga a pensar no trabalho das recreadoras com elas mesmas e com os bebês e/ou com as crianças. Reconhece que a ação das recreadoras pode ser considerada como uma forma de cuidar do cuidado de si, na medida em que possibilita e estimula o desenvolvimento de uma atenção da criança sobre si. Nesse sentido, destaca que "o bebê é cuidado, mas ele também aprende um modo de cuidar, um trabalho sobre si” (2011, p. 68).

O artigo de Freitas (2010) explora o cuidado de si e a criação de novas formas de vida, problematizando os processos de subjetivação por meio das chamadas "práticas de si". O autor nos lembra de que "a tematização dos processos de subjetivação, nos trabalhos tardios de Foucault, (...) [implicou] um modo singular de pensar a constituição do sujeito ético" (ÉVRARD apud FREITAS, 1995/2010, p. 169-170). Afirma ainda que ao estudar as técnicas de si e as práticas de si e sua potencialidade na criação de novas formas de vida na atualidade, "Foucault observa a constituição de sujeitos singulares. Sujeitos não mais constituídos mediante práticas que o sujeitam, denotando antes uma subjetivação ética irredutível aos mecanismos disciplinares e às regulações normalizadoras da biopolítica" (FREITAS, 2010, p. 170).

Em linhas gerais, o autor evidencia em seu texto "como a experiência ética que o sujeito faz de si mesmo é inseparável do processo político de sua formação, ao mesmo tempo que apresenta a noção de 'cuidado de si' como ponto de partida para expressar uma nova articulação entre filosofia e educação" (FREITAS, 2010, p. 170).

Face a compreensão da existência de um esgotamento da experiência formativa no projeto da modernidade, nos remete ao texto platônico Alcibíades propondo-o como paradigma da formação mediada pelo cuidado de si e conclui afirmando que

\begin{abstract}
Mobilizar-se para reivindicar e lutar pela concretização do direito à educação também deve ser uma manifestação de preocupação e cuidado de si. O governo democrático da educação pode ser praticado e reconhecido na busca do cuidado de si, contribuindo para reduzir os espaços de sujeição, já que a ética do cuidado de si aposta no exercício prático da liberdade (FREITAS, 2010, p. 186).
\end{abstract}

Pagni (2010), por sua vez, problematiza o governo das crianças exercido pela pedagogia na modernidade e analisa o seu potencial de resistência, mobilizando para isso os conceitos foucaultianos de governamentalização e de cuidado de si. Pondera que "o mesmo sentido das questões de Sócrates a Alcebíades poderiam ser dirigidas aos educadores e, portanto, a nós mesmos, na atualidade" (p. 113), e nos propõe refletir sobre a possibilidade de que as crianças sejam tomadas como mestres do cuidado de si no processo educativo.

Esta perspectiva é inovadora na medida em que não apenas nos permite pensar o cuidado de si e do outro exercido pelas pessoas responsáveis por cuidar de bebês e crianças como explorado por Freitas (2010) e por Guimarães (2011), como também nos oferece a possibilidade de pensar no papel dos próprios bebês e crianças processo formativo que atravessa o cuidado de si.

A obra organizada por DeLoache e Gottlieb (2000), intitulada A World of babies é provocativa, nesse sentido e nos permite pensar que, assim como Alcibíades desejava governar 
seu povo, uma mulher grávida e um futuro pai, desejam governar seus filhos/as. Cuidar de si, de seu corpo e de sua alma, nesse sentido, é fundamental para poder cuidar do outro. A obra de DeLoachee Gottlieb evidencia os modos distintos como diferentes povos se relacionam com a espiritualidade, com o corpo, com o governo de si e dos bebês, bem como, algumas vezes o papel dos bebês no governo de si dos adultos (como no caso dos Balineses que consideram que os bebês são deuses reencarnados). Os vários modos como os bebês são compreendidos por povos distintos é certamente um tema que merece novos estudos para aprofundamento e discussão. O mesmo vale para os modos como compreendemos a educação de bebês e das crianças, de um modo geral e o papel que tais práticas assumem numa perspectiva do cuidado de si. Os artigos que integram esta seção do dossiê contribuem nesse sentido.

\section{Referências}

ABRAMOWICZ, A.; TEBET, G. G. C. Educação infantil: um balanço a partir do campo das diferenças. Pro-Posições, v. 28, p. 182-203, 2017.

DeLOACHE, J.; GOTTLIEB, A. A world of babies: imagined childcare guides for seven societies. Cambridge University Press, 2000

FOUCAULT, M. Microfísica do poder. Org. e Tradução de R. Machado. Rio de Janeiro: Edições Graal, 1979.

FOUCAULT, M. A hermenêutica do sujeito. $3^{\mathrm{a}}$ ed. São Paulo: WMF Martins Fontes, 2011.

FREITAS, A. S. Michel Foucault e o "cuidado de si": a invenção de formas de vida resistentes na educação. Educação Temática Digital, v. 12 (1), 167-190. Disponível em: 〈https://nbnresolving.org/urn:nbn:de:0168-ssoar-212279>.

GALLO, S. Biopolítica e subjetividade: resistência? Educar em Revista, v. 33, n. 66, p. 77-94, $2017 \mathrm{a}$.

GALLO, S. Políticas da diferença e políticas públicas em educação no Brasil. Educação e Filosofia, v. 31, n. 63, p. 1497-1523, 2017 b.

GOTTLIEB, A. Tudo começa na outra vida: a cultura dos recém nascidos no oeste da África. São Paulo: FAP - UNESP, 2012

GUIMARÃES, D. Relações entre bebês e adultos na creche: o cuidado como ética. 2011.

NAKANO, A. M. S.; MAMEDE, M. V. A prática do aleitamento materno em um grupo de mulheres brasileiras: movimento de acomodação e resistência. Rev. latino-am. enfermagem, v. 7, n. 3, p. 69-76, julho 1999. Disponível em: 〈http://www.scielo.br/pdf/rlae/v7n3/13478>. Acesso em: 27 de dezembro de 2018.

OLIVEIRA, F.; ABRAMOWICZ, A. Educação e diferença na direção da multidão. In: ABRAMOWICZ, A.; VANDENBROECK, M. (Org.). Educação infantil e diferença. Campinas: Papirus, 2013. 
PAGNI, P. Â. Infância, arte de governo pedagógica e cuidado de si. Educação e Realidade, v. 35, n. 3, p. 99-123, 2010. Disponível em: <http://hdl.handle.net/11449/114952>. Acesso em: 27 de dezembro de 2018. 